\title{
Monitoring biofilm formation by using cyclic voltammetry - effect of the experimental conditions on biofilm removal and activity
}

\author{
M.S. Gião*, M.I. Montenegro** and M.J. Vieira* \\ * Centro de Engenharia Biológica-IBQF, Universidade do Minho, 4710-057, Braga, Portugal \\ ** Centro de Química-IBQF, Universidade do Minho, 4710-057, Braga, Portugal
}

\begin{abstract}
The effect of experimental conditions on cyclic voltammetry experiments on platinum electrodes covered with biofilms formed by Pseudomonas fluorescens for 2 hours was investigated. Results show that recycling the potential stabilizes the shape of the cyclic voltammogram after 135 cycles, but the observation of the electrodes by epifluorescence microscopy showed that cells are still adhered to the platinum surface. Some experimental conditions were changed during the electrochemical measurements - sweep rate, $\mathrm{pH}$ of the buffer and applied potential range. Some of these parameters had a strong impact on the bacteria that are adhered to the surface, increasing the death and removal in some circumstances.
\end{abstract}

Keywords Biofilm monitoring; cyclic voltammetry; electrodes; Pseudomonas fluorescens; removal; viability

\section{Introduction}

The unwanted accumulation of biofilms in industrial equipment is a natural phenomenon, due to the favourable conditions of nutrients, temperature and availability of microorganisms. The early detection of biofouling may allow the application of more effective strategies to eradicate biofilms. It is widely recognised that there is a need for on-line monitoring techniques that are reliable, easy to implement and cheap, to detect biofilm formation during continuous operation (Kahlre and Flemming, 2000, Licina et al., 1994). Electrochemical techniques have been applied to a number of investigations in surface fouling by bacteria (Mittelmann et al., 1992; Illsley et al., 1997; Cachet et al., 2000).

The technique used in this work is repetitive cyclic voltammetry applied to a planar electrode of small area. Cyclic voltammetry is a method well-known for its role in analytical chemistry, allowing a large number of organic, inorganic and biological compounds to be determined and quantified. Therefore, it may also provide a convenient means of detecting the early stages of biofilm accumulation on the surface. When the electrode is clean and cyclic voltammetry is applied to the electrode (see details in materials and methods section), the current plotted versus electrode potential is a cyclic voltammogram with four peaks as depicted in Figure 1. Peaks 1 and 4 correspond, respectively, to desorption and adsorption of hydrogen and peaks 2 and 3 correspond, respectively, to the platinum oxide formation and reduction.

The present work presents results obtained on the application of cyclic voltammetry to platinum electrodes with and without biofilm formed by Pseudomonas fluorescens on the surface. Calibration was carried out by the direct observation of the biofilm present on the electrode surface by epifluorescence, prior to and after cyclic voltammetry.

\section{Material and methods}

Microorganism, cell growth and biofilm development

Pseudomonas fluorescens ATCC 13525, a Gram-negative aerobic bacteria, was used throughout this work. A cylindrical glass vessel (height $13 \mathrm{~cm}$, diameter $10 \mathrm{~cm}$ and a 


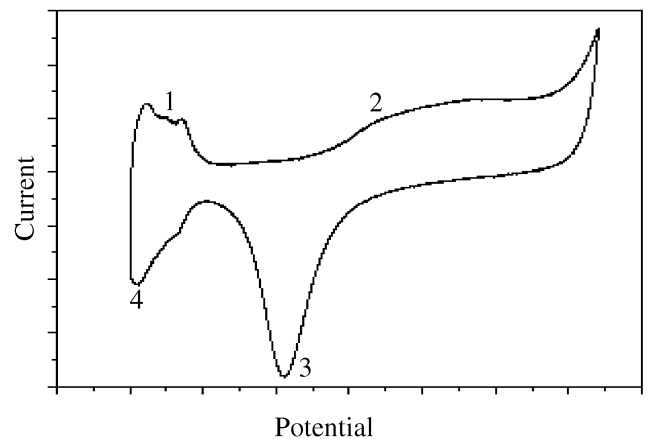

Figure 1 Cyclic voltammogram at a platinum electrode. Peaks 1 and 4 correspond, respectively, to adsorption and desorption of hydrogen, and peaks 2 and 3 correspond, respectively, to the adsorption and desorption of oxygen

working volume of $0.5 \mathrm{~L}$ ), well stirred, was used as the reactor to form biofilms on the surface of the platinum electrode. It was inoculated with bacteria in the exponential phase of growth. The system was continuously fed with a sterile medium containing $50 \mathrm{mg} \mathrm{L}^{-1}$ glucose, $25 \mathrm{mg} \mathrm{L}^{-1}$ peptone and $12.5 \mathrm{mg} \mathrm{L}^{-1}$ yeast extract in phosphate buffer (PB). The platinum electrodes (working electrodes) were immersed in the fermenter during 2 hours (eight electrodes were used for each condition tested). These electrodes with biofilm on their surface were used to carry out the electrochemical measurements and the observations under epifluorescence microscope. Prior to their utilisation, the electrodes were degreased, rinsed twice with water and sterilised using ethanol before being cleaned electrochemically.

\section{Electrochemical experiments}

The electrochemical technique used was repetitive cyclic voltammetry at a platinum electrode. The working electrodes were platinum discs with $1 \mathrm{~mm}$ diameter (area of the sensor: $7.85 \times 10^{-7} \mathrm{~m}^{2}$ ). The electrodes were prepared by sealing a platinum wire into a glass tube and the internal end of the platinum wire was sealed to a copper wire that provided the external contact. The cross-section of the platinum was polished with alumina powder, on a polishing cloth. The reference electrode was a Metrohm silver/silver chloride electrode and all the data are reported versus this reference. The auxiliary electrode was a platinum spiral. The cyclic voltammetry experiments were carried out in a two-compartment, three-electrode cell at room temperature using a potentiostat Autolab type PGSTAT 10, Ecochemie that produced a repeating triangular function.

Each electrode, with and without biofilm, was electrochemically treated by immersion in the solution of interest. The potential was recycled between the appropriate limits, using different operating conditions, namely the $\mathrm{pH}$ of the buffer, the sweep rate and the potential limits. The experimental procedure included recording of the cyclic voltammograms for each uncolonized electrode, and the immersion of the electrodes in the fermenter to allow biofilm formation on the surface of the electrodes. Then, the electrode was recycled between pre-selected limits for approximadely 30 minutes, and this procedure was followed by microscopic visualisation of the electrode surface.

The time scale of the measurements depends on the sweep rate and on the applied potential range. For the normal conditions (sweep rate: $250 \mathrm{mV} \mathrm{s}^{-1}$, applied potential range: -0.5 to $1.0 \mathrm{~V}$ ) a scan lasts 12 seconds.

\section{Epifluorescence observations}

The platinum electrodes were visualized under epifluorescence microscopy after staining the surface with the BacLight viability kit, Molecular Probes. The two BacLight stains, 
SYTO 9 and propidium iodide, dissolved in DMSO, were mixed together $(130 \mu \mathrm{l}+130 \mu \mathrm{l})$, placed on the surface of the electrode and incubated for $15 \mathrm{~min}$. The electrodes were observed under epifluorescence (viable cells were fluorescent green, while dead cells were fluorescent red).

\section{Results}

\section{Detection of biofilm by cyclic voltammetry}

The height of the hydrogen desorption peak obtained after the first scan seems to be strongly dependent on the biofilm age. Figure 2 presents the first scan for biofilms formed on the surface of platinum electrodes for 2, 4 and 24 hours, and it can be concluded that the older the biofilm (and consequently, the higher the coverage of the surface) the smaller is this peak.

Figure 3 shows that when cyclic voltammetry is applied to a platinum electrode that was immersed for 2 hours in a $50 \mathrm{ppm}$ growth medium without bacteria (described in materials and methods section), the first scan indicates, by comparison with the voltammogram that characterizes the clean electrode (that may be used as the fingerprint of the electrode) that some molecules were adsorbed on the surface. After 95 scans the voltammogram obtained approaches the voltammogram at a clean surface.

Concerning the biofilm with 2 hours, Figure 4 shows that the height of the hydrogen desorption peak of the voltammogram is sensitive to the presence of a deposit on the surface. Moreover, the number of scans needed to obtain a reproducible voltammogram is much higher in this case, than for the case presented in Figure 3.

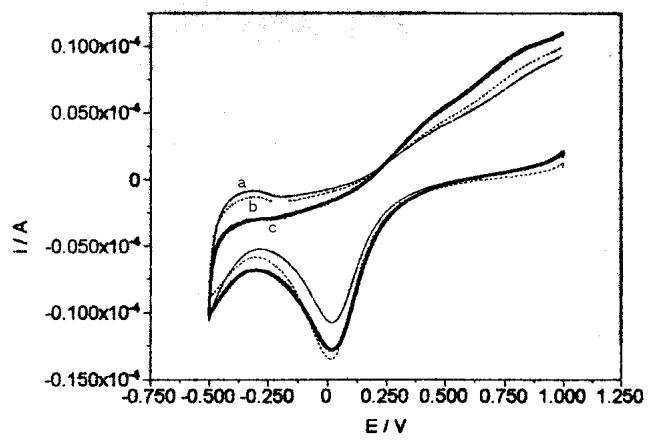

Figure 2 First scan of cyclic voltammograms obtained at a platinum electrode in phosphate buffer solution (scan rate $0.25 \mathrm{mV} \mathrm{s}^{-1}$ ): a) electrode covered with a biofilm grown for 2 hours; b) electrode covered with a biofilm grown for 4 hours; c) electrode covered with a biofilm grown for 24 hours

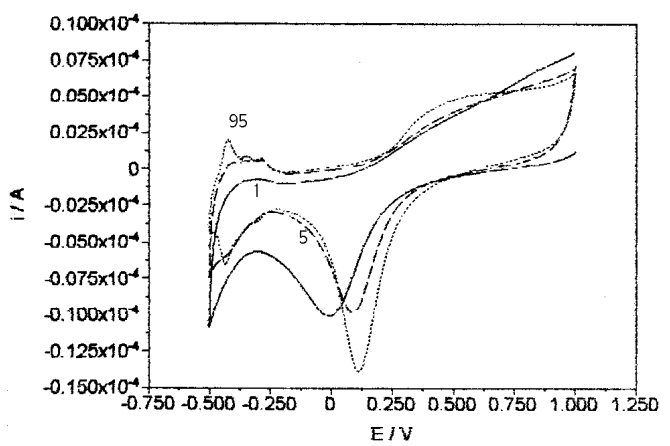

Figure 3 Cyclic voltammetry when: a) electrode immersed in $50 \mathrm{ppm}$ medium. Cyclic voltammograms were obtained after 1,5 and 95 scans 


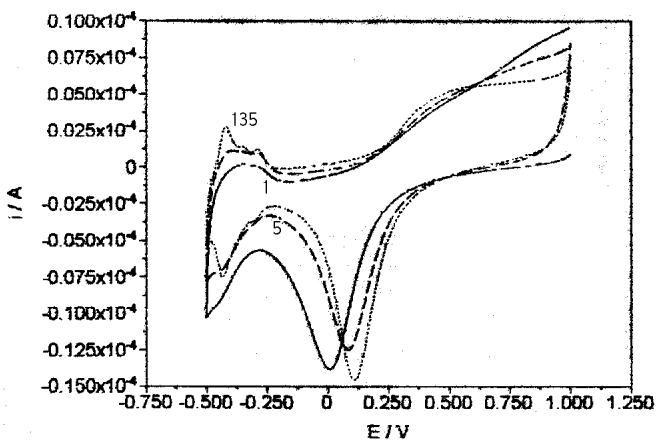

Figure 4 Cyclic voltammetry on an electrode with a 2 hour biofilm on the surface. Cyclic voltammograms were obtained after 1 scan, 5 scans and 135 scans

\section{Effect of the experimental conditions on the activity and removal of bacteria from the surface}

Figure 5 shows: (a), the surface of the electrode prior to biofilm formation; (b), an electrode with a 2 hour biofilm on the surface; and (c), a platinum electrode with a 2 hours biofilm on the surface after cycling the potential. These micrographs were obtained by epifluorescence microscopy, after staining the surfaces with BacLight viability kit. This figure demonstrates that a biofilm is formed after 2 hours. However, the observation of the platinum electrode surface after cycling the electrode potential for 150 scans indicates that, for the experimental conditions used (phosphate buffer $\mathrm{pH} 7$, sweep rate $250 \mathrm{mV} \mathrm{s}^{-1}$, and potential applied from -0.5 to $1.0 \mathrm{~V}$ ), the biofilm was not completely removed from the surface and part of the remaining cells on the surface are active, as shown by the differences in colour of the cells present on the surface.

Effect of the sweep rate. The observation by epifluorescence of the electrode surfaces presented in Figure 6 shows that a change of the sweep rate from $150 \mathrm{mV} \mathrm{s}^{-1}$ to $500 \mathrm{mV} \mathrm{s}^{-1}$ increases the number of dead cells on the surface (more red cells are present on the surface), but the removal is less effective than that obtained for the normal conditions (Figure 6c)). Conversely, lower sweep rates favour the removal of cells from the surface, but most of the cells remaining on the surface are viable (Figure 6a)).

Effect of the $\mathrm{pH}$. Experiments carried out in phosphate buffer $\mathrm{pH} 4$ showed that in these conditions, the cleaning is more effective. In fact, the bacterial cells on the surface are almost all dead only by immersion in $\mathrm{pH} 4$ (Figure 7a). Some of the bacteria can be removed by the application of cyclic voltammetry using the same $\mathrm{pH}$ (Figure 7b). Using $\mathrm{pH} 7$ during cyclic voltammetry, the cells are apparently removed to a less extent (Figure 7c).

Effect of the applied potential range. Figure 8 shows that an increase on the positive potential to $1.5 \mathrm{~V}$, does not clean the electrode further but all the bacterial cells are dead. Conversely, with a negative increase to $-2.0 \mathrm{~V}$ the surface is almost clean, in spite of the fact that a few viable cells are still on the platinum surface (Figure $8 \mathrm{c}$ ). When this potential was applied, hydrogen bubbles were formed at the surface of the electrode, which removed the bacteria mechanically.

\section{Discussion and conclusions}

Results obtained show that cyclic voltammetry can be very useful in the detection of biofilm formation, as demonstrated in Figure 2: the older the age of the biofilm, the smaller is the hydrogen desorption peak of the voltammogram obtained for the first scan. It should 


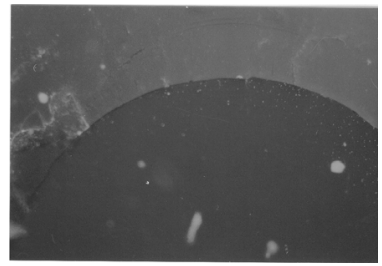

(a)

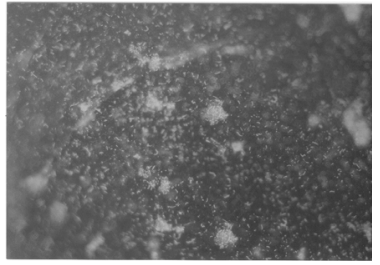

(b)

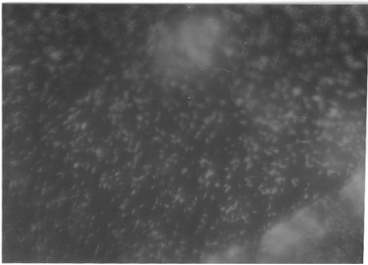

(c)

Figure 5 Epifluorescence micrographs of a platinum electrode surface of the electrode: a) prior to biofilm formation; b) electrode with a 2 hour biofilm on the surface; c) a platinum electrode with a 2 hour biofilm on the surface after cycling for $30 \mathrm{~min}$ in $\mathrm{PB} \mathrm{pH} \mathrm{7,} \mathrm{sweep} \mathrm{rate} 250 \mathrm{mV} \mathrm{s}^{-1}$, and potential applied from -0.5 to $1.0 \mathrm{~V}$

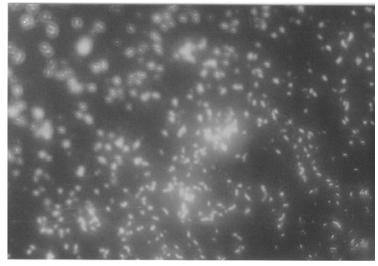

(a)

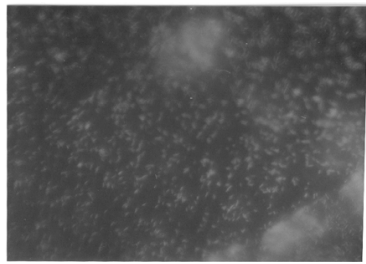

(b)

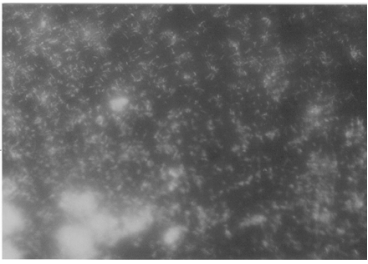

(c)

Figure 6 Epifluorescence micrographs of a platinum electrode after 150 scans of cyclic voltammetry in PB $\mathrm{pH} 7$, potential applied from -0.5 to $1.0 \mathrm{~V}$, and sweep rate a) $150 \mathrm{mV} \mathrm{s}^{-1}$; b) $250 \mathrm{mV} \mathrm{s}^{-1}$; c) $500 \mathrm{mV} \mathrm{s}^{-1}$

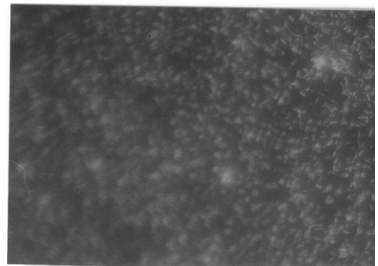

(a)

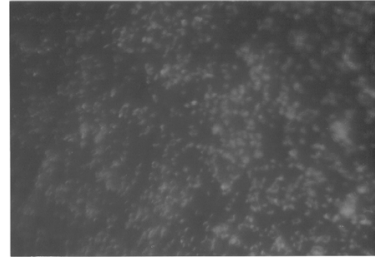

(b)

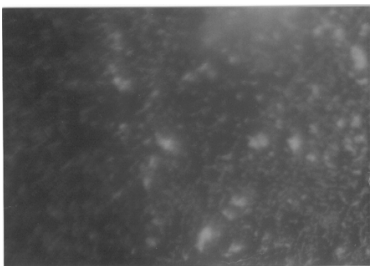

(c)

Figure 7 Epifluorescence micrographs of a platinum electrode a) after 30 minutes immersed in $\mathrm{pH} 4$; after cyclic voltammetry in b) $\mathrm{pH} 4$; c) $\mathrm{pH} 7$

be stressed that this sensor can detect molecules adsorbed on the surface (Figure 3). Figures 3 and 4 present the effect of recycling the potential on the characteristics of the voltammograms. It should be noticed that as the potential is cycled between the pre-set limits the pattern of the voltammograms approaches that corresponding to an uncolonized surface. The evolution of the voltammogram shape as the potential is cycled may constitute a means of providing information on the coverage of the surface since the area under the peaks increases as the biofilm is partially removed. Results show that, when a 2 hours biofilm is on the surface, recycling the potential stabilizes the shape of the cyclic voltammogram after 135 cycles, but the observation of this electrode by epifluorescence microscopy showed that cells are still adhered to the platinum surface (Figure 5). However, some cells are dead after the process. The results presented in Figures 6-8 show that the experimental conditions such as sweep rate, buffer $\mathrm{pH}$ and applied potential range, may have a strong impact on the bacteria that are adhered to the surface. Figure 6 shows that an increase in sweep rate removes less bacteria and the remaining cells are found dead, while at lower scan rates the opposite is true. Figure 7 displays the $\mathrm{pH}$ effect and it can be shown that a high $\mathrm{pH}$ favours the bacterial removal. Finally Figure 8 shows that a large negative potential limit yields the formation of bubbles, which are able to mechanically remove the bacteria from the surface. These results may be explained by the possible formation in situ, at the platinum electrode, 


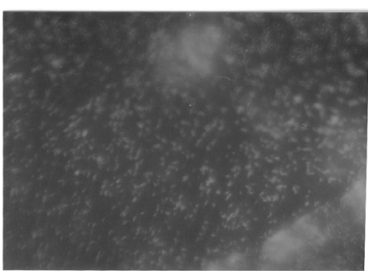

(a)

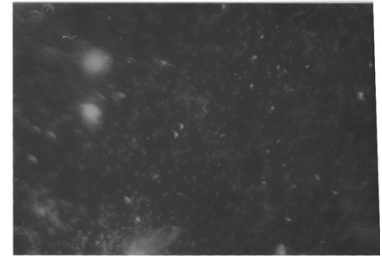

(b)

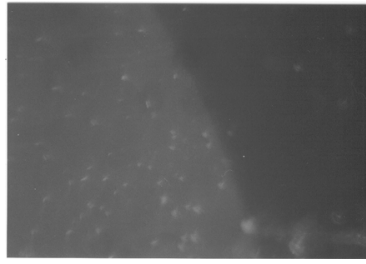

(c)

Figure 8 Epifluorescence micrographs of a) a platinum electrode after 30 minutes of cyclic voltammetry with a potential applied from -0.5 to $1.0 \mathrm{~V} ; \mathrm{b}$ ) a platinum electrode after 30 minutes of cyclic voltammetry with a potential applied from -0.5 to $1.5 \mathrm{~V}$; c) a platinum electrode after 1.5 minutes of cyclic voltammetry with a potential applied from -2.0 to $1.0 \mathrm{~V}$

of products ( such as $\mathrm{H}_{2} \mathrm{O}_{2}$ ) that may act as biocides, and with application of potentials that may give rise to higher electrostatic repulsions (bacteria are negatively charged in these conditions) and thus favour detachment from the surface and formation of bubbles that mechanically remove the bacteria from the surface.

\section{Acknowledgements}

The authors acknowledge the financial support provided by IBQF and FCT/MCT through Project POCTI/34945/EQU/2000.

\section{References}

Cachet, H., Moustafid, T.E., Herbert-Guillou, D., Festy, D., Touzain, S. and Tribollet, B. (2000).

Characterization of deposits by direct observation and by electrochemical methods on a conductive transparent electrode. Application to biofilm and scale deposit under cathodic protection. EMRC2000, Proc 7th Inter Symp on Electrochemical Methods in Corrosion Research, Budapest, Hungary, Keynote paper 22.

de Beer, D., van den Heuvel, J.C. and Ottengraf, S.P.P. (1993). Microelectrode measurements of the activity and distribution in nitrifying aggregates. Appl. Environ. Microbiol., 59(2), 573-579.

Draisci, R., Volpe, G., Lucentini, L., Cecilia, A., Federico, R. and Palleschi, G. (1998). Determination of biogenic amines with an electrochemical biosensor and its application to salted anchovies. Food Chem., 62(2), 225-232.

Illsley, R.A., Roscoe, S.G., Jackson, E.D. and Hughes, T.J. (1997). An electrochemical investigation of the fouling of a model surface by a coliform bacterium. Biofouling, 11(3), 191-199.

Klahre, J. and Flemming, H.-C. (2000). Monitoring of biofouling in papermill process waters. Wat. Res., 34(14), 3657-3665.

Licina, G.J., Nekoksa, G. and Howard, R.L. (1994). An electrochemical method for on-line monitoring of biofilm activity using the Biogeorge probe. In Kearns, J.F., Little, B.J. (eds) Microbiologically influenced corrosion, ASTM, STP 1232, Philadelphia, pp. 118-127.

Mittelman, M.W., Kohring, L.L. and White, D.C. (1992). Multipurpose laminar-flow adhesion cells for the study of bacterial colonization and biofilm formation. Biofouling, 6, 39-51. 